\title{
Editorial
}

\section{Economia espacial e memória na América Latina}

\author{
Everaldo Batista da Costa ${ }^{1}$ \\ René Alejandro Gonzalez Rego ${ }^{2}$
}

\author{
(c) (1) (\$) $\Theta$ \\ DOI: https://doi.org/10.26512/patryter.v2i3.23320
}

É com muito entusiasmo que apresentamos o terceiro número da PatryTer - Revista Latinoamericana e Caribenha de Geografia e Humanidades. No mês de março de 2019, completamos o primeiro ano de existência. Os três primeiros números publicados revelam o grande desafio assumido pela equipe de edição e esboçam os enfrentamentos que temos pela frente, por diferentes motivos.

Certamente, o maior desafio, nesses doze primeiros meses, foi o de iniciar e manter a revista sem apoio financeiro de qualquer agência nacional ou estrangeira. Todo o trabalho do periódico é realizado por integrantes do Grupo de Pesquisa $C N P q$ Cidades e Patrimonializacao na América Latina e Caribe 3 , sediado no Departamento de Geografia da Universidade de Brasilia e também coordenado pelo editor chefe da PatryTer. Lembro da colaboração incondicional de colegas de diferentes partes de nossa América, especialmente de Costa Rica, México, Cuba, Panamá, Argentina, Peru e Colômbia. Prova disso é que o presente número será apresentado no III Seminário Latinoamericano sobre Representacoes do Espaço, no Instituto de Geografía da UNAM, México, no mês de abril de 2019.

Outro importante desafio enfrentado pela revista se revelou no processo de difusão, para recebimento de artigos, de forma a diversificar e a qualificar a publicação. Então, vinculado a sua difusão, outro repto foi o de receber, avaliar e aprovar artigos correspondentes à demanda ou escopo temático da PatryTer, que diz respeito às dinâmicas territoriais urbanas, rurais e meio-ambientais na América Latina e Caribe. O incentivo da PatryTer, para os próximos anos, é o de apresentar ao público um referencial continental de reflexão sobre as muitas problemáticas advindas das intervenções espaciais urbanas, rurais e meio-ambientais na América Latina e Caribe; qualquer outro logro poderá ser consequência dessa missão que assumimos.

É muito importante, em nosso primeiro ano de existência comemorado, recordar tanto o conteúdo da revista quanto o sentido concreto da grafia PatryTer, o que já foi apresentado em nosso Projeto Político-Acadêmico [publicado no primeiro volume, segundo número, divulgado em outubro de 2018, http://periodicos.unb.br/index.php/patryter/article/view/12298 ]:

La grafía PatryTer trae el sentido bolivariano de la Patria Grande 4 como unidad continental y de integración territorial, las cuales se singularizan por la forma y el contenido de las ciudades, el campo y la dominación hegemónica de la "naturaleza", en América Latina y el Caribe. Ciudades, campo y "naturaleza" (como referentes geográficos) que tienen resignificado un sinnúmero de patrimonios populares y mundiales [lo urbano y lo rural - específicos de la región - son nuestro mayor patrimonio, cuando la masa de la población habita y reproduce sus vidas en las periferias de las ciudades y del campo].

\footnotetext{
${ }^{1}$ Docente do Departamento de Geografia da Universidade de Brasília. Editor-Chefe da Patry'Ter. Email: everaldocosta@unb.br. ORCID: https://orcid.org/0000-0003-0734-6680

2 Docente da Faculdade de Geografia da Universidad de La Habana. Membro do Conselho Editorial da PatryTer. Email: rgrego@geo.uh.cu. ORCID: https://orcid.org/0000-0002-9544-8363

${ }^{3}$ Doutores, doutorandos e mestrandos relacionados na página do Conselho Técnico da PatryTer.

${ }^{4}$ Termo criado pelo argentino Manuel Ugarte, em seu livro La pátria grande, de 1922, o qual tratou da tese da unificación hispano-americana.
} 
Intencionalmente, a capa do vol. $2, \mathrm{n}^{\circ} 3$ da revista apresenta uma fotografia da Ex Hacienda Nueva Italia, no México (foto 01), a qual evidencia um dos artigos apresentados no número, da mexicana Ilia Alvarado Sizzo. Este artigo apresenta argumentos e elementos transversais presentes nos demais trabalhos agora publicados, levando-nos a considerá-lo um número dedicado a economia espacial e memória na América Latina. A fazenda Nova Itália foi uma grande propriedade privada (de imigrantes italianos) com 36 mil hectares que, no início do século XX, converteu-se em Ejido Coletivo, por força do Estado, simbolizando o movimento nacional e latinoamericano pela reforma agrária. Propriedade da terra, condições de trabalho, cotidiano familiar, agricultura, escalas de poder, memória individual e coletiva, interação cidade-campo, representações do espaço etc. são dimensões de debates centrais nos artigos publicados. Por economia espacial entendemos o complexo sistema de produção material mediado pelo trabalho e gerador de valor(es) depositados nos lugares; ainda, nossa perspectiva de economia espacial, que se vislumbra nesse novo número, não dicotomiza matéria e ideia, produção e imaginário, necessidades e utopias vinculadas ao território enquanto aporte e suporte de usos, de apropriações, de potencias e de violências escalares, mas também de memória.

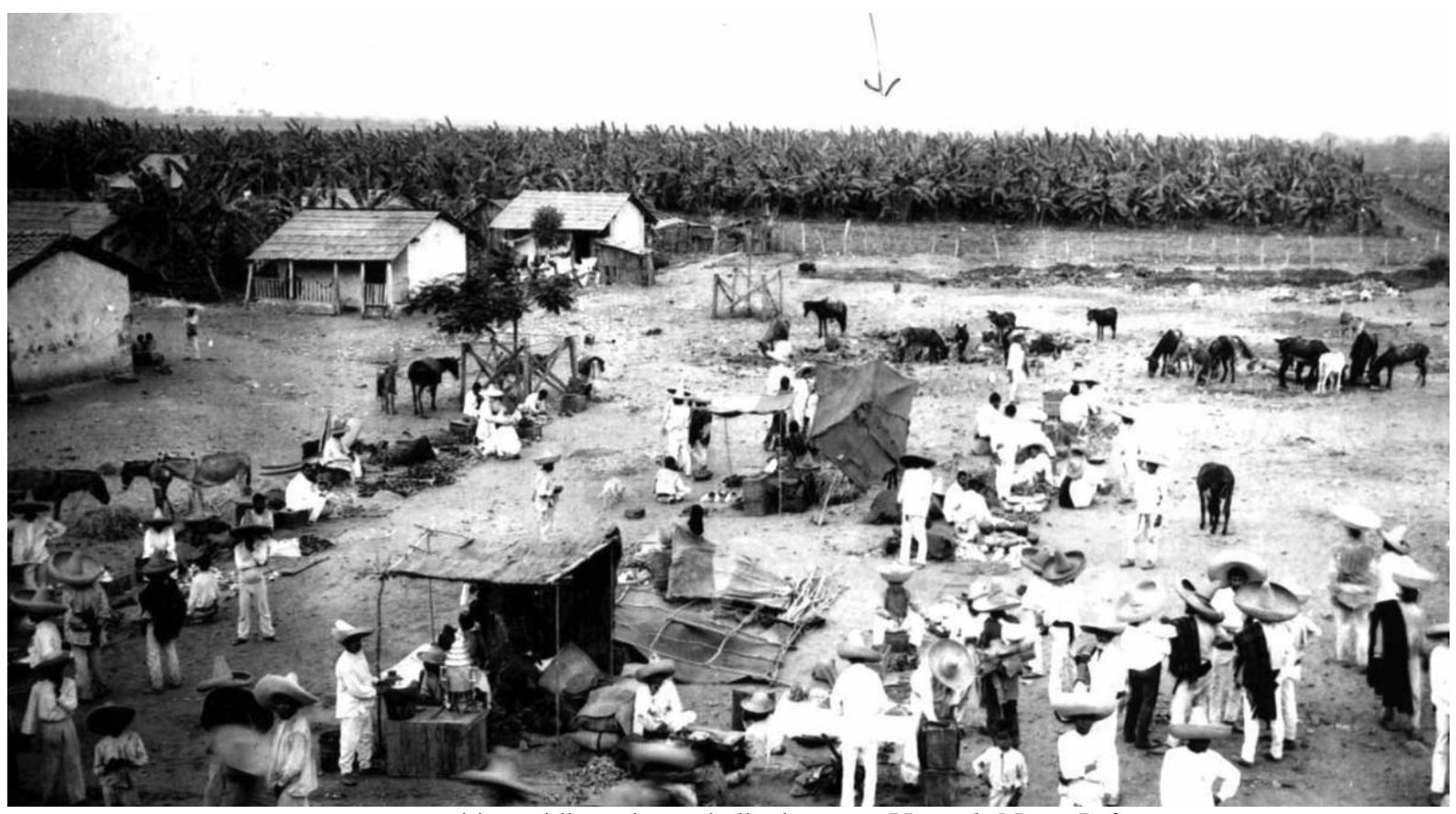

Foto 01 - Vida cotidiana dos trabalhadores na Hacienda Nueva Itália.

Foto: Acervo privado da família Cusi (proprietários da fazenda).

O terceiro número da PatryTer congrega artigos de professores(as) e de pesquisadores(as) do Panamá, do México e do Brasil, alinhados com a economia espacial no continente, em vieses teóricometodológicos diversificados.

Ensaio teórico pela patrimonialização do espaço banal (Eduardo Abdo Yázigi), Territorio, memoria e imaginario del trabajo, caso en el México (Ilia Alvarado Sizzo), Ciberespaco e patrimonio cultural digital (Júlio César de Lima Ramires), Patrimonio, territorio e memoria, caso en el Panamá (Maria Adames de NewBill), Cartografia, dinâmica territorial e patrimonio material (Adriano Bittencourt Andrade e José Jackson Andrade), A produção canavieira e o mito do progresso (Lara Cristina Gomes Ferreira e Fernando Luiz Araújo Sobrinho), Patrimonio-territorial e saber local (Rúbia de Paula Rúbio), Arquitetura en el centro histórico de Ciudad de México, caso de La Merced (Boris Tapia Peralta, Raúl Salas Espíndola, Mónica Cejudo Collera, Miguel Hierro Gómez) constituem os atuais artigos publicados que, em alguma medida, nos remetem a dimensões da economia pelo espaço na América Latina. Seguirá este editorial uma homenagem que fazemos ao amigo, professor e intelectual Eduardo Abdo Yázigi, que por mais de meio século contribuiu com o pensamento geográfico crítico brasileiro e, neste mês de fevereiro de 2019, desencarnou. Yázigi nos brindou com um artigo meses antes de sua passagem, o qual abre este novo número. 
Por fim, cabe comentar que esta revista segue com a missão de divulgar a pluralidade existente no pensamento geográfico crítico e o saber de outas disciplinas preocupadas com as muitas dimensões do espaço latinoamericano e caribenho. Essa tarefa, nos dias atuais, constitui um ato político, de resistência e confiança no futuro, não somente pelas dificuldades de recursos e entraves ideológicos que enfrentamos dentro de nossas universidades, mas, o que é pior, (onde só com a exceção das universidades cubanas) pela política de Estado neoliberal alinhada com a ideologia de uma modernização e de um progresso às avessas, os quais nossos países (e universidades, em contradição com sua missão) incorporaram, a passos largos, no transcurso da formação territorial e psicossocial latinoamericana. O caso brasileiro é emblemático, no âmbito de uma economia espacial que segrega os mais pobres e fragmenta o território em todas as escalas; nosso caso é, infelizmente, nos dias atuais, emblemático, com universidades públicas atacadas e desprestigiadas por ideologias que tentam, a todo custo, aniquilar o pensamento social crítico e humanista dentro e fora da instituição.

Independentemente do quadro dibujado pelo poder do Estado, no Brasil e outros países do continente, a PatryTer seguirá confiando que o conhecimento atinado de nossas realidades territoriais é a forma mais potente de significar a esperança de autonomia, de paz, de desenvolvimento, de liberdade e de democracia na América Latina!

Estas sanas intenções que brinda a PatryTer para o que José Martí definiu como Nuestra América, tem condicionado que a mesma tenha uma cálida acolhida por parte dos colegas cubanos, os quais se comprometem, nas próximas edições, a ter uma maior presença, para poder compartir com os leitores suas experiencias e principais desafios aos que se tem enfrentado no campo da docência e da pesquisa geográficas e demais ciências humanas, em especial no referido às dinâmicas territoriais, ambientais, urbanas ou rurais.

Uma ótima leitura para todo(as)!

\section{*Agradecemos aos avaliadores dos artigos publicados no vol. 2, $\mathrm{n}^{\circ} 3$ da PatryTer.}

Bernadete Castro (Universidade Estadual Paulista, Brasil), Leonardo Civale (Universidade Federal de Viçosa, Brasil), Tania Herrera (Pontificia Universidad Catolica del Peru), Flaviana Lira (Universidade de Brasília, Brasil), Leandro Benedini Brusadin (Universidade Federal de Ouro Preto, Brasil), Rúbia de Paula Rúbio (Universidade de Brasília, Brasil), Ilia Alvarado Sizzo (Universidad Nacional Autónoma de México, México), Roberto Silva de Souza (Universidade Estadual de Alagoas, Brasil), Victor Pacheco Garrido (Universidade de Brasília, Brasil), Amaya Larrucea Garritz (Universidade Nacional Autónoma de México). 